\title{
Cognitive and Psychosocial Improvements Following Aripiprazole Augmentation of SSRI Antidepressant Therapy in Treatment Refractory Depression: A Pilot Study
}

\author{
Tracy L. Greer ${ }^{*}$, Prabha Sunderajan, Bruce D. Grannemann, Madhukar H. Trivedi \\ Department of Psychiatry, The University of Texas Southwestern Medical Center, Dallas, USA \\ Email: "tracy.greer@utsouthwestern.edu
}

Received June 28 $8^{\text {th }}, 2013$; revised August $1^{\text {st }}, 2013$; accepted August $10^{\text {th }}, 2013$

Copyright (C) 2013 Tracy L. Greer et al. This is an open access article distributed under the Creative Commons Attribution License, which permits unrestricted use, distribution, and reproduction in any medium, provided the original work is properly cited.

\begin{abstract}
Functional impairments are a common concern for individuals with major depressive disorder (MDD) that does not resolve with initial antidepressant treatment. Such concerns include cognitive difficulties, such as impaired executive functions, which can be particularly disruptive to daily function. There is a need to evaluate potential augmentation strategies for depressed individuals who do not adequately respond to initial antidepressant treatment. Aripiprazole is an FDA-approved adjunctive treatment to antidepressants for MDD, and because of its effect on both dopaminergic and serotonergic systems, may be of particular benefit to cognitive functioning. This study evaluated depressive symptom severity, cognitive function, and psychosocial function before and after six weeks of open-label aripiprazole augmentation treatment in patients with MDD who did not fully respond to selective serotonin reuptake inhibitor treatment. Participants endorsed difficulty with concentration and decision-making at study entry. Significant decreases were observed for depressive symptoms, and significant increases were found in executive function measures and measures of psychosocial function and quality of life. These preliminary data suggest that aripiprazole augmentation may yield functional benefits when used as an adjunctive treatment in MDD, and support the need for further investigation of aripiprazole and other augmentation strategies to specifically evaluate functional outcomes in MDD.
\end{abstract}

Keywords: Neurocognition; Psychosocial Function; Major Depressive Disorder; Treatment Resistance

\section{Background}

Major depressive disorder (MDD) is a debilitating, chronic disorder that is of worldwide concern (Cuijpers et al., 2012), particularly since it is estimated to become the most burdensome disease in high-income countries, and second-most overall, by the year 2030 (Mathers \& Loncar, 2006). The consensus of treatment guidelines for major depressive disorder is that the goal of treatment should be symptomatic remission, which is characterized by minimal absence of depressive symptoms (Davidson, 2010). However, it is often the case that despite achieving remission, residual symptoms remain that are still bothersome to those with MDD, and if left untreated may contribute to further decline and relapse. In fact, greater than $90 \%$ of remitters have at least one residual symptom (Nierenberg et al., 2010), and cognitive impairments are a common residual symptom. Even with adequate symptomatic treatment response (McClintock et al., 2011) and remission (Nierenberg et al., 2010; Zimmerman et al., 2012) of overall depressive symptoms, cognitive impairments remain a concerning residual symptom warranting treatment.

Cognitive impairments in depression are most frequently noted on tasks assessing executive function, declarative memory, and attention (Veiel, 1997; Landro et al., 2001). Impaired

*Corresponding author. cognitive function in depression has been strongly associated with disability in depression and many other psychiatric disorders (Jaeger et al., 2006). Disruptions in cognitive function can have wide reaching implications on quality of life, affecting many areas of life such as relationships, work, school, and management of basic needs (e.g., taking care of finances and other life responsibilities). Because of the negative consequences of functional impairments, an alternative goal to symptomatic remission is achieving wellness (Keller, 2003; McIntyre et al., 2006), which incorporates restoration of function in addition to symptomatic and pathophysiologic change. To achieve such a goal, it is imperative that the field begins to include functional measures and targeted treatments for specific symptoms to improve the quality of life and functioning of depressed individuals (Greer et al., 2010). Some potential treatments for cognitive impairments such as psychostimulants and cholinesterase inhibitors have yielded benefits in some cases, but they often are associated with unwanted side effects, and they require significant monitoring (Greer et al., 2010; Kurian et al., 2009). Thus, it is critical to continue identifying treatments that will improve cognition and other functional outcomes in depressed individuals.

Aripiprazole is an FDA-approved adjunctive treatment to antidepressants for MDD. When added to ongoing antidepressant treatment that is not fully resolving depressive symptoms, 
aripiprazole increases the likelihood of remission (Berman et al., 2009; Nelson et al., 2012). It is well-tolerated, even after longterm (e.g., a year) administration, with primary side effects being weight gain, akathisia, and fatigue (Berman et al., 2011). However, the ability for aripipriazole to address specific functional outcomes has been sparsely investigated. Thase et al. (2008) examined mean changes in the Sheehan Disability Scale (SDS) scores between depressed individuals augmented with aripiprazole vs. placebo and found that aripiprazole augmentation was associated with significantly greater reductions in mean SDS scores, as well as with the individual items measuring symptom interference with social and family life. The effect of aripiprazole augmentation on health-related quality of life and health utility has been compared to augmentation with other atypical antipsychotics based on data from the National Health and Wellness Survey, and aripiprazole augmentation showed significantly greater benefits in measures of mental health, general health, emotional role limitations, bodily pain, and health utility (Kalsekar et al., 2012). To our knowledge, no study has examined cognitive changes as an outcome following aripiprazole augmentation. Reimherr et al. (2010) conducted a pooled analysis examining symptom-level improvements in core symptoms of depression as measured by the Montgomery-Asberg Depression Rating Scale (MADRS) and the Inventory for Depressive Symptomatology, Self-Report (IDS-SR). They did not find that aripiprazole augmentation was superior to placebo augmentation on concentration symptoms as measured by the items addressing that symptom on either scale; however, it is not clear how many participants endorsed concentration difficulties at baseline.

Aripiprazole has a distinct pharmacological profile that has been speculated to explain its efficacy as an augmentation agent (Nelson et al., 2008), and supports the possibility of improved cognitive function as well. Aripiprazole is unique from other antipsychotics in that it stabilizes both dopaminergic and serotonergic systems. It affects serotonergic activity via mechanisms that are identical to agents that have been established as effective antidepressants. Specifically, aripiprazole is a partial agonist at $5-\mathrm{HT}_{1 \mathrm{~A}}$ receptors and an antagonist at $5-\mathrm{HT}_{2}$ receptors (Burris et al., 2002). In comparison to other commonly used atypical or typical antipsychotic agents, aripiprazole has a higher affinity for $5-\mathrm{HT}_{1 \mathrm{~A}}$ receptors, and has an affinity for $5-\mathrm{HT}_{2}$ receptors that is higher than or comparable to most other antipsychotics agents (surpassed only by risperidone and ziprasidone) (Burris et al., 2002; Bymaster et al., 1996; Seeger et al., 1995). Aripiprazole is also a partial agonist of both $D_{2}$ and $D_{3}$ dopaminergic receptors (Tadori et al., 2008). $\mathrm{D}_{2}$ and $\mathrm{D}_{3}$ agonism has been associated with pro-cognitive effects, and has shown some promise in improving cognition as an adjunctive treatment in bipolar disorder (Burdick et al., 2012).

This study examined open-label aripiprazole augmentation of selective serotonin reuptake inhibitor (SSRI) treatment in depressed individuals who endorsed difficulties with concentration and decision-making that were significant enough to disrupt their functioning. This study was conducted to gather preliminary data for assessment of the following: 1) the effect of aripiprazole augmentation on depressive symptom severity, psychosocial function and cognitive function, and 2) the relationship between psychosocial function and cognitive function in MDD. We hypothesized that aripiprazole augmentation would be associated with reductions in symptom severity, and with improved performance on measures of psychosocial and cognitive function, particularly measures of executive function.

\section{Study Design}

\section{Participants}

The study protocol and informed consent form were approved by the University of Texas Southwestern Medical Center at Dallas Institutional Review Board. Eligible participants with major depressive disorder were treated in the community with one of three SSRIs (escitalopram, citalopram, or sertraline) for 8 - 12 weeks and experienced residual depressive symptoms that prompted them to seek additional treatment and respond to study advertisements. The Structured Clinical Interview for DSM-IV Axis I Disorders, Clinician-Rated version (SCID-CV) was used to diagnose MDD and rule out excluded comorbid psychiatric disorders. Residual symptoms were quantified as a Hamilton Rating Scale for Depression, 17-item, $\left(\mathrm{HRSD}_{17}\right)$ score of 14 or greater or a Clinical Global Impression ScaleSeverity (CGI-S) score of 3 or greater. Participants had to report difficulties with concentration or cognition and score 2 or greater on the 30-item Inventory for Depressive Symptomatology-Clinician-Rated (IDS- $\mathrm{C}_{30}$ ) item measuring this symptom (\#15: Concentration and Decision Making). Organic cognitive deficits that could confound study outcomes were ruled out using the Mini-Mental State Examination (MMSE). Additional exclusions included the presence of an untreated or unstable comorbid medical condition, known cardiovascular disease or seizure disorder, certain comorbid psychiatric disorders (current or past psychotic disorder, bipolar disorder, schizophrenia or schizoaffective disorder, anorexia, bulimia, obsessive compulsive disorder, alcohol or substance abuse or dependence within the last 6 months, or high suicide risk), or concomitant pharmacological or psychotherapeutic treatment. A urine pregnancy test was performed as clinically indicated for women who were able to have children and wished to participate in this research.

Eligible participants completed a comprehensive baseline assessment battery that included measures of depressive symptoms, psychosocial function, and cognitive function, as described below.

\section{Assessment of Depressive Symptoms}

The $\mathrm{HRSD}_{17}$ and IDS Self-Report (IDS-SR 30 ) were used to assess severity of depressive symptoms at screening, baseline, and weekly thereafter. The $\mathrm{HRSD}_{17}$ (Hamilton, 1960) is a clinician-administered rating scale designed to assess the severity of symptoms in patients diagnosed with depression and is the most widely used symptom severity measure for depression. The IDS-SR $_{30}$ (Rush et al., 1986) is a 30-item, depression-specific symptom severity rating scale designed to measure the specific signs and symptoms of depression, including melancholic and atypical features. Scores range from 0 to 84 with higher scores representing greater severity of depressive symptoms.

\section{Assessment of Psychosocial Function}

The Short-Form Health Survey (SF-36) (Ware \& Snow, 1993) was used to assess quality of life and general health. This measure is comprised of two major subscales: Mental and Physical. The Quality of Life Enjoyment and Satisfaction Questionnaire, General Activities (Q-LES-Q) (Endicott \& Nee, 1993) was used to measure satisfaction and enjoyment in various 
domains of function: physical health, feelings, work, household duties, school/course work, leisure time activities, and social relations. The Work and Social Adjustment Scale (WSAS) (Mundt et al., 2002) was used to identify functional impairment attributed to depression. The WSAS is a 5-item self-report, and each question is rated on a 0 to 8 scale, with 0 indicating no impairment, and 8 indicating very severe impairment. The WSAS has acceptable internal consistency (Cronbach's alpha $=.70$ to .94$)$ and test re-test reliability $(\mathrm{r}=.73)$. WSAS scores above 20 suggest moderately severe or worse psychopathology. These measures were collected at baseline, Week 3, and Week 6.

\section{Assessment of Cognitive Function}

The National Adult Reading Test-Revised (NART-R) (Blair \& Spreen, 1989) was given at baseline to assess premorbid intelligence. Clinician-rated and self-reported cognitive function was assessed via the Inventory for Depressive Symptomatology item "Concentration and Decision Making". The Cambridge Neuropsychological Test Automated Battery (CANTAB) (Cambridge Cognition Limited, 2004) was used to assess preand post-treatment cognitive function. CANTAB is a comprehensive neuropsychological testing battery that has been used to assess cognitive function in a wide variety of brain disorders, including mood disorders. Tasks selected for use in this study have previously shown performance differences between depressed patients and healthy controls. The tasks selected represented each of the following domains: Attention, Visual Memory, Executive Function/Set-shifting and Working Memory, Executive Function/Spatial Planning, Decision Making and Response Control, and Verbal Learning and Memory. These tasks measure domains (attention, perception, working memory, declarative memory, effortful control) that are consistent with those included in the National Institute of Mental Health Research Domain Criteria (NIMH RDoC) initiative (Sanislow et al., 2010), which aims to re-assess pathophysiology of chronic mental illnesses through a dimensional approach (Insel et al., 2010). An overall description of each task assessed in this study is provided below.

1) Attention Domain Tasks: Motor Screening (MOT)screens for visual, movement and comprehension difficulties; Big Circle/Little Circle (BLC) — a simple attention measure that tests comprehension, learning and reversal of a rule; Reaction Time (RTI) - measures speed of response to both predictable and unpredictable visual stimuli;

2) Visual Memory Domain Tasks: Delayed Matching to Sample (DMS) - an object recognition task using complex visual patterns in which the choice is presented either simultaneously with the sample or after a brief delay; Paired Associates Learning (PAL) - a delayed response visual memory and learning task; Pattern Recognition Memory (PRM) - assesses visual spatial recognition memory;

3) Executive Function/Set-Shifting and Working Memory Domain Tasks: Intradimensional/Extradimensional Shift (IED) - examines set-shifting and flexibility of attention by testing both simple and more complex rule acquisition and reversal; Spatial Working Memory (SWM) - an executive function task assessing retention and manipulation of items in working memory, with the ability for assessment of perseverative (redundant) errors;

4) Executive Function/Spatial Planning Domain Task:
Stockings of Cambridge (SOC) - an executive function task based on the Tower of London test that assesses spatial planning;

5) Decision Making and Response Control Domain Task: Affective Go/No-go (AGN) - assesses information processing biases and inhibitory control for positive and negative stimuli;

6) Verbal Learning and Memory Domain Task: Verbal Recognition Memory (VRM) - a measure of immediate and delayed verbal recall and recognition.

Each task can generate multiple outcome measures (e.g., percent correct, response latency), as described in Table 1. The CANTAB battery was administered at baseline and following six weeks of aripiprazole augmentation treatment by raters who were blinded to symptom severity assessments.

\section{Medication Management and Assessment of Safety}

Participants were maintained on their entry-level dose of SSRI and a flexible dose of $5 \mathrm{mg}$ to $15 \mathrm{mg}$ aripiprazole was added to their SSRI for 6 weeks. Participants started at $5 \mathrm{mg}$ and went up to $15 \mathrm{mg}$ only if clinically indicated and not contraindicated due to adverse effects. Participants met with a study psychiatrist on a weekly basis during aripiprazole augmentation for assessment of suicidality, side effects, adverse events, and improvement. Vital signs were recorded at each visit. The Frequency, Intensity, and Burden of Side Effects Ratings (FIBSER) and Patient Rated Inventory of Side Effects (PRISE) scales were used to assess side effects. The FIBSER assesses the frequency, intensity, and degree of functional impairment associated with side effects of treatment, and the PRISE assesses specific types of side effects (e.g., sleep, sexual function), which may or may not be associated with treatment. Participants were assessed for possible abnormal involuntary movements or extrapyramidal symptoms at every visit.

\section{Statistical Analyses}

The primary aim of the study was to determine the effect of aripiprazole augmentation on depressive symptom severity, psychosocial function and cognitive function. Changes in depressive symptom severity and psychosocial function were assessed via t-tests. Distributions of scores on the cognitive measures were evaluated and due to the non-normal distributions of some measures, a non-parametric Signed Rank test was used to evaluate changes in the cognitive measures. Because this is a pilot study, results are reported if they were significant at $p<.05$.

A secondary aim of the study was to assess the relationship between changes in depressive symptoms, psychosocial function and cognitive function. Due to the size of the sample and the non-normal distribution of some variables, we conducted a series of Spearman rank correlations between the changes in cognitive measures that were significant (post-pre treatment) and changes from baseline to Week 3 and Week 3 to Week 6 on the depressive symptom severity and psychosocial function measures.

Completion of the study was required for analyses since cognitive data were obtained only at pre- and post-treatment timepoints.

\section{Results}

All participants provided written informed consent. Twenty- 


\section{T. L. GREER ET AL.}

Table 1.

Description of cognitive function outcome measures.

\begin{tabular}{|c|c|c|c|}
\hline Task & Acronym & Outcome Measure & Description \\
\hline \multicolumn{4}{|c|}{ Training and Screening Attention Tasks } \\
\hline \multirow[t]{2}{*}{ Big/Little Circle } & BLC & Mean correct latency (ms) & $\begin{array}{l}\text { Speed of response showing how quickly subject touched the correct stimulus after it was } \\
\text { displayed on the screen }\end{array}$ \\
\hline & & Mean percent correct $(\%)$ & Percent of total correct responses \\
\hline \multirow[t]{2}{*}{ Reaction Time } & RTI & Five-choice movement time (ms) & Time taken to touch correct stimulus after release of the press pad \\
\hline & & Five-choice reaction time (ms) & Speed with which subject releases press pad in response to stimulus at one of five locations \\
\hline \multicolumn{4}{|l|}{ Visual Memory } \\
\hline \multirow[t]{3}{*}{$\begin{array}{l}\text { Delayed Matching to } \\
\text { Sample }\end{array}$} & DMS & Percent correct (all delays) $(\%)$ & Percent of correct stimulus selection after stimulus was hidden at delays of $0 \mathrm{~s}, 4 \mathrm{~s}$, and $12 \mathrm{~s}$ \\
\hline & & $\begin{array}{l}\text { Percent correct (simultaneous) } \\
(\%)\end{array}$ & $\begin{array}{l}\text { Percent of correct stimulus selection during simultaneous presentation of target stimulus } \\
\text { and distractors }\end{array}$ \\
\hline & & Mean correct latency (all delays) & $\begin{array}{l}\text { Average speed of response where correct stimulus was selected in trials with simultaneous } \\
\text { presentation of target stimulus and distractors }\end{array}$ \\
\hline \multirow[t]{3}{*}{$\begin{array}{l}\text { Paired Associates } \\
\text { Learning }\end{array}$} & PAL & Mean trials to success & $\begin{array}{l}\text { Total number of trials required to correctly locate patterns/number of successfully } \\
\text { completed stages }\end{array}$ \\
\hline & & Total errors (adjusted) & Total number of errors with adjustment for each stage not attempted due to previous failure \\
\hline & & Total trials (adjusted) & Total number of presentation required to correctly locate patterns in all stages \\
\hline \multirow[t]{2}{*}{$\begin{array}{l}\text { Pattern Recognition } \\
\text { Memory }\end{array}$} & PRM & Percent correct & Percent correct responses \\
\hline & & Mean correct latency (ms) & Mean time to respond correctly \\
\hline
\end{tabular}

\section{Executive Function}

Intra/Extra

Dimensional

Set-Shifting

IED Stages completed

Number of stages completed out of nine possible

\section{Pre-ED errors}

EDS errors

Spatial Working

Memory

\section{SWM Strategy}

Between errors $(4,6$, and 8 boxes)

Executive Function/Spatial Planning

Stockings of

Cambridge

SOC

Problems solved in minimum

moves

Mean initial thinking time $(2,3$,

4 , and 5 moves)

Mean subsequent thinking time

(2, 3, 4, and 5 moves)

Decision Making and Response Control

Affective Go/No-Go AGN Mean correct latency

Total omissions

Total commissions

\section{Verbal Learning and Memory}

Verbal Recognition

Memory
VRM

Immediate free recall total correct

Immediate free recall total novel Total number of words recalled immediately following presentation of word list that were words

Immediate free recall total perseverations

Immediate recognition total correct

Immediate recognition total false Total number of distractors endorsed as correct responses during presentation of word list positives

Delayed recognition total correct

Delayed recognition total false positives

Total number of words correctly recalled immediately following presentation of word list not a part of the list

Total number of times a previously correctly recalled is repeated immediately following presentation of word

Total number of words correctly recalled during presentation of word list that includes correct targets and distractors that includes correct targets and distracters

Total number of words correctly recalled during presentation of word list that includes Total number of distractors endorsed as correct during presentation of word list that
Number of errors prior to the extra-dimensional shift

Errors made in the extra-dimensional stage

Calculated based on number of times participant begins a search with the same box for 6and 8-box problems. Lower score indicates better use of strategy.

Times the subject revisits a box in which a token was previously found; errors calculated for 4-, 6-, and 8-box trials

Number of times subject successfully completed a test problem in the minimum possible number of moves

Time taken to plan a problem solution for trials requiring 2,3, 4, and 5 moves

Speed of movement after the initial move has been made for trials requiring $2,3,4$, and 5 moves.

Mean time taken to respond correctly to each target word stimulus in all assessed blocks Total number of missed responses to targets in all assessed blocks

Total number of responses to distractors in all assessed blocks correct targets and distractors following 20 min delay from original presentation of word list includes correct targets and distractors following $20 \mathrm{~min}$ delay from original presentation of 
six participants were screened for participation, and nine participants were found to be ineligible for the following reasons: presence of significant comorbid medical condition or abnormal laboratory values (4), presence of other psychiatric disorder or severity of symptoms (2), declined further participation (2), and prohibited concomitant medication (1). Seventeen participants began augmentation treatment with aripiprazole. Thirteen participants completed all six weeks of aripiprazole augmentation and thus were included in the analyses. Baseline demographic and clinical characteristics of the study participants are provided in Table 2.

\section{Depressive Symptom Severity}

Significant mean reductions in depressive symptom severity over the six weeks of aripiprazole augmentation were obtained on both clinician-rated and self-report measures of depression (see Figure 1). HRSD showed a mean difference of -11.38 $( \pm 4.3 ; \mathrm{t}=9.52, p<.0001)$ and IDS-SR a mean difference of $-17.54( \pm 11.64 ; \mathrm{t}=5.43, p=.0002)$ between baseline and post-treatment. Of the thirteen completers, nine $(53 \%)$ responded, defined by a $50 \%$ or greater reduction in HRSD score. Seven $(41 \%)$ remitted, as defined by achieving HRSD score of 7 or less.

\section{Psychosocial Function}

Significant improvements in psychosocial function over the six weeks of aripiprazole augmentation were obtained for the Q-LES-Q and SF-36, and showed a trend toward significance for the WSAS. On the Q-LES-Q, the pre-treatment mean of $2.73 \pm .69$ significantly increased to $3.49 \pm .97$ post-treatment, a mean change of $.81 \pm .48(\mathrm{t}=5.84, p=.0001)$. SF-36 scores significantly increased from $39.62 \pm 11.63$ at pre-treatment on the Mental subscale to $63.75 \pm 28.05$ post-treatment, a mean change of $24.17 \pm 25.30(\mathrm{t}=3.31, p=.007)$, and from $68.50 \pm$ 22.83 at pre-treatment on the Physical subscale to $82.92 \pm$ 14.84 post-treatment, a mean change of $15.79 \pm 22.75(\mathrm{t}=2.40$, $p=.035)$. On the WSAS, scores also improved, with a mean score of $26.67 \pm 8.51$ at pre-treatment, decreasing to $17.67 \pm$ 14.19 , with a trend toward significance (mean difference $=$

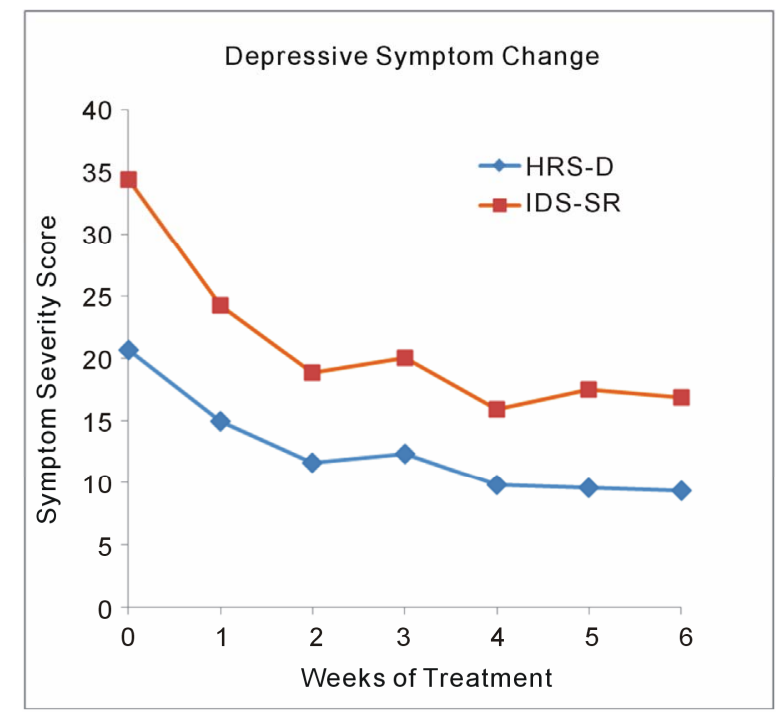

Figure 1.

Clinician-rated (HRSD) and self-reported (IDS-SR) depressive symptom severity significantly decreased with aripiprazole augmentation. HRSD pre-treatment mean $(\mathrm{SD})=20.7$ (5.0), posttreatment mean $=9.3(6.3)$; IDS-SR pre-treatment mean $=34.9$ (9.9), post-treatment mean $=17.5(11.6)$.

Table 2.

Baseline sample characteristics.

\begin{tabular}{|c|c|c|}
\hline Baseline Variable & $\begin{array}{c}\text { MEAN OR \% ( } \pm \text { SD) } \\
n=17\end{array}$ & $\begin{array}{l}\text { MEAN OR \% ( } \pm \text { SD) } \\
n=13\end{array}$ \\
\hline Age (years) & $48.18( \pm 7.95)$ & $50.46( \pm 7.34)$ \\
\hline Male (\%) & 23.53 & \\
\hline Female $(\%)$ & 76.47 & \\
\hline White (\%) & 82.35 & \\
\hline Hispanic (\%) & 17.65 & \\
\hline Education (years) & $11.81^{*}( \pm 4.75)$ & $12.42^{+}( \pm 4.60)$ \\
\hline \multicolumn{3}{|l|}{ Characteristics of Depression } \\
\hline Age of MDD Onset & & $28.62( \pm 11.48)$ \\
\hline Number of Previous Episodes & $3.65( \pm 4.86)$ & $3.85( \pm 5.58)$ \\
\hline Length of Current Episode (months) & $65.24( \pm 60.72)$ & $67.38( \pm 67.44)$ \\
\hline \multicolumn{3}{|l|}{ Baseline Symptom Severity } \\
\hline HRSD17 & $20.00( \pm 4.50)$ & $20.69( \pm 4.97)$ \\
\hline IDS-C30 & $34.65( \pm 7.11)$ & $34.85( \pm 7.76)$ \\
\hline IDS-SR30 & & $34.38( \pm 9.95)$ \\
\hline \multicolumn{3}{|l|}{ Estimated Intelligence } \\
\hline NART & & $104.85( \pm 9.02)$ \\
\hline
\end{tabular}

${ }^{*} \mathrm{n}=16,{ }^{+} \mathrm{n}=12 ; \mathrm{MDD}=$ Major Depressive Disorder; $\mathrm{HRSD}_{17}=$ Hamilton Rating Scale for Depression, 17-item; IDS-C $\mathrm{C}_{30}=$ Inventory for Depressive SymptomatologyClinician-Rated, 30 -item; IDS-SR 30 = Inventory for Depressive Symptomatology-Self-Report, 30-item; NART = National Adult Reading Test. 


\section{T. L. GREER ET AL.}

$7.82 \pm 11.74, \mathrm{t}=2.21, p=.0516)$. Note that higher scores indicate better function for the Q-LES-Q and SF-36 measures, whereas lower scores indicate better function on the WSAS.

\section{Cognitive Function}

Significant changes in cognitive function were observed on measures of executive function. Significant changes on difference scores were found on the Stockings of Cambridge Mean Initial Thinking Time for 3-(S $=-35.5, p<.02)$ and 5 -move ( $\mathrm{S}$ $=-34.5, p<.02$ ) problems (Figure 2(a)). Interestingly, they were not observed for 4-move problems, perhaps due to a trade-off between speed and accuracy, although this is only speculative. Between errors (akin to perseverative errors) on the Spatial Working Memory (SWM) task were significantly reduced following aripiprazole augmentation for 6-move problems $(\mathrm{S}=-33.0, p<.007)$, and were in the expected direction for 8-move problems. The Spatial Working Memory Strategy score, which represents efficiency in completing the working memory task, also significantly improved following aripiprazole augmentation $(\mathrm{S}=-23.5, p<.04)$ (lower score $=$ more efficient use of strategy) (see Figure 2(b)). No significant changes were observed on measures of attention, visual or verbal learning and memory, or decision making and response control.

\section{The Relationship between Changes in Depressive Symptom Severity, Psychosocial Function, and Executive Function}

When the relationship between changes among symptom severity, psychosocial function, and executive function tasks were evaluated, an interesting pattern of results was observed. Changes in depressive symptom severity occurred primarily early in treatment, with the greatest reductions observed between baseline and Week 3 , and smaller additional reductions occurring between Weeks 3 and 6 . In contrast, many of the psychosocial function measures showed the greatest improve-

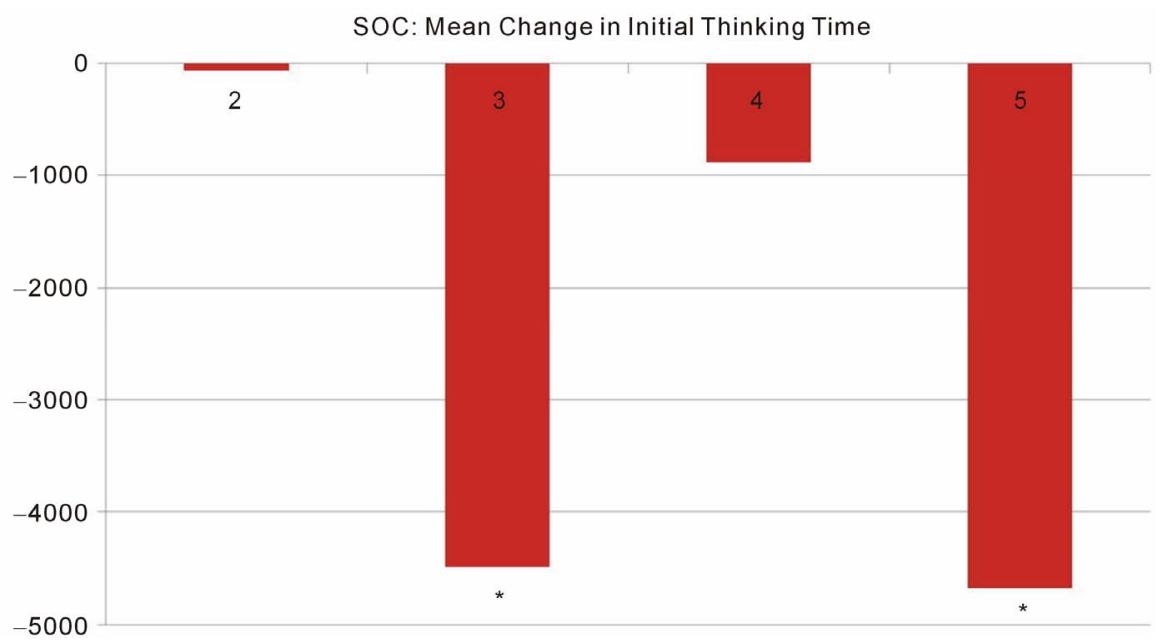

(a)

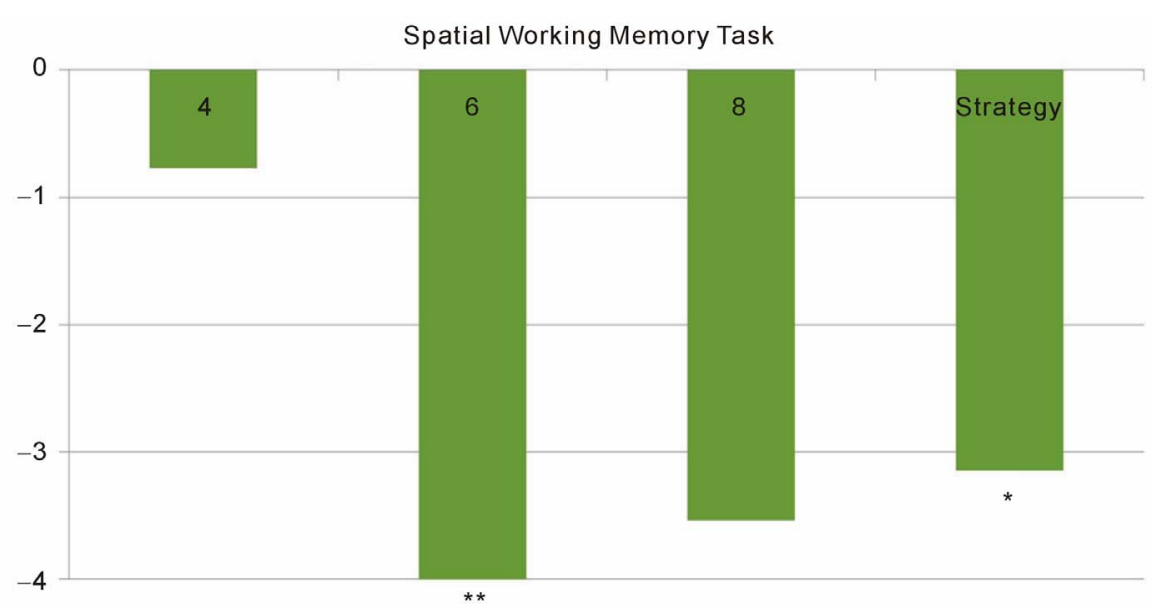

(b)

Figure 2.

Executive Function Changes Following Aripiprazole Augmentation. Mean initial thinking time (in ms) was significantly decreased following aripiprazole augmentation on the Stockings of Cambridge task (SOC) for 3- and 5-move problems (top panel). On the spatial working memory task, the number of errors was significantly reduced on 6-move problems, and the strategy score significantly improved (bottom panel). "Significant at $p<.05 ;{ }^{* *}$ Significant at $p<.01$ 
ments in the later weeks of treatment (i.e., between Weeks 3 and 6). There were no significant correlations between depressive severity and executive function measures that improved with aripiprazole augmentation. Interestingly, the majority of significant correlations between psychosocial function and changes in executive function occurred in the last three weeks of treatment, suggesting that cognitive changes are occurring following the greatest reductions in symptom severity and in conjunction with the greatest changes in psychosocial function (see Table 3). Although the timing of these changes is not exclusively limited to a specific time interval, these data warrant further investigation in a larger sample.

\section{Safety and Tolerability}

Four participants who began aripiprazole augmentation discontinued treatment due to side effects, which included: akathisia, feeling "spaced out", dizziness, chest pain, sedation, weight gain, restlessness and drowsiness. Side effects measured by the PRISE are reported in Table 4 . Adverse effects reported at $30 \%$ or more of study visits include poor concentration, difficulty sleeping, fatigue, loss of sexual desire, restlessness, decreased energy, anxiety, headache, and constipation.

\section{Discussion}

The results of this study support significant functional improvements, in addition to significant reductions in depressive symptoms, in quality of life, psychosocial function, and executive functioning following aripiprazole augmentation in MDD.

Table 3.

Significant correlations between change in executive function and change in psychosocial function.

\begin{tabular}{|c|c|c|c|}
\hline \multicolumn{4}{|c|}{ Week 0 to Week 3} \\
\hline $\begin{array}{l}\text { Psychosocial } \\
\text { Measure }\end{array}$ & $\begin{array}{c}\text { SOC Mean } \\
\text { Initial Thinking } \\
\text { Time } \\
\text { (3-moves) }\end{array}$ & $\begin{array}{c}\text { SOC Mean } \\
\text { Initial Thinking } \\
\text { Time } \\
\text { (5-moves) }\end{array}$ & SWM Strategy \\
\hline $\begin{array}{c}\text { Q-LES-Q } \\
\text { Household Duties }\end{array}$ & & & -.65 \\
\hline $\begin{array}{l}\text { Q-LES-Q Leisure } \\
\text { Time Activities }\end{array}$ & & & -.57 \\
\hline Q-LES-Q Work & & & -.89 \\
\hline $\begin{array}{l}\text { SF-36 Bodily } \\
\text { Pain }\end{array}$ & & & -.58 \\
\hline \multicolumn{4}{|c|}{ Week 3 to Week 6} \\
\hline $\begin{array}{l}\text { Psychosocial } \\
\text { Measure }\end{array}$ & $\begin{array}{c}\text { SOC Mean } \\
\text { Initial Thinking } \\
\text { Time } \\
\text { (3-moves) }\end{array}$ & $\begin{array}{c}\text { SOC Mean } \\
\text { Initial Thinking } \\
\text { Time } \\
\text { (5-moves) }\end{array}$ & SWM Strategy \\
\hline $\begin{array}{c}\text { Q-LES-Q } \\
\text { Physical Health }\end{array}$ & & -.68 & -.62 \\
\hline Q-LES-Q Work & & & \\
\hline $\begin{array}{l}\text { SF-36 Social } \\
\text { Function }\end{array}$ & -.74 & & \\
\hline SF-36 Vitality & & & -.66 \\
\hline $\begin{array}{l}\text { SF-36 Health } \\
\text { Change }\end{array}$ & & & -.59 \\
\hline
\end{tabular}

$\overline{\mathrm{SOC}}=$ Stockings of Cambridge; $\mathrm{SWM}=$ Spatial Working Memory; Q-LES-Q $=$ Quality of Life Enjoyment and Satisfaction Questionnaire; SF-36 = Short-Form Health Survey.
In addition, aripiprazole augmentation was generally well-tolerated. We believe the results of this study support further investigation of the utility of aripiprazole in improving functional outcomes, including executive function, through a larger, controlled trial.

Table 4.

Adverse effects as measured by the PRISE.

\begin{tabular}{|c|c|c|}
\hline Adverse Effect & Percent & Frequency \\
\hline \multicolumn{3}{|l|}{ Gastrointestinal } \\
\hline Diarrhea & 18.0 & 20 \\
\hline Constipation & 30.6 & 34 \\
\hline Dry mouth & 16.2 & 18 \\
\hline Nausea/Vomiting & 5.4 & 6 \\
\hline \multicolumn{3}{|l|}{ Cardiovascular } \\
\hline Heart palpitation & 7.2 & 8 \\
\hline Dizziness on standing & 4.5 & 5 \\
\hline Chest pain & 2.7 & 3 \\
\hline \multicolumn{3}{|l|}{ Skin } \\
\hline Rash & 1.8 & 2 \\
\hline Increased perspiration & 18.9 & 21 \\
\hline Itching & 3.6 & 4 \\
\hline Dry skin & 6.3 & 7 \\
\hline \multicolumn{3}{|l|}{ Nervous System } \\
\hline Headache & 36.9 & 41 \\
\hline Tremors & 9.9 & 11 \\
\hline Poor coordination & 7.2 & 8 \\
\hline Dizziness & 6.3 & 7 \\
\hline \multicolumn{3}{|l|}{ Eyes/Ears } \\
\hline Blurred vision & 10.8 & 12 \\
\hline Ringing in ears & 13.5 & 15 \\
\hline \multicolumn{3}{|l|}{ Genital/Urinary } \\
\hline Difficulty urinating & 5.4 & 6 \\
\hline Painful urination & 1.8 & 2 \\
\hline Frequent urination & 10.8 & 12 \\
\hline Menstrual irregularity & 4.5 & 5 \\
\hline \multicolumn{3}{|l|}{ Sleep } \\
\hline Difficulty sleeping & 49.5 & 55 \\
\hline Sleeping too much & 26.1 & 29 \\
\hline \multicolumn{3}{|l|}{ Sexual Functioning } \\
\hline Loss of sexual desire & 46.0 & 51 \\
\hline Trouble achieving orgasm & 9.9 & 11 \\
\hline Trouble with erection & 0.9 & 1 \\
\hline \multicolumn{3}{|l|}{ Other } \\
\hline Anxiety & 38.7 & 43 \\
\hline Poor concentration & 59.0 & 65 \\
\hline General malaise & 22.5 & 25 \\
\hline Restlessness & 41.4 & 46 \\
\hline Fatigue & 47.8 & 53 \\
\hline Decreased energy & 39.6 & 44 \\
\hline
\end{tabular}

Note that occurrences are reported by percent occurrence and frequency across all observed visits $(\mathrm{n}=111)$, PRISE $=$ Patient Rated Inventory of Side Effects. 
The study was limited by the fact that it was an open-label trial in a small sample, and the results should be evaluated in that context. There are however, strengths in the study design that are relevant to future examinations of cognitive function in depression. A major strength of the study was the endorsement of cognitive complaints as an inclusion criterion. However, it is true that subjective reports of cognitive deficits do not necessarily translate to objective impairment. It is our belief, however, that relying solely on objective verification of impairment at baseline may well miss the opportunity to observe clinically meaningful improvements in cognitive function. Baseline impairment need not necessarily be one or two standard deviations below normed scores to be a clinically relevant departure from an individual's typical score when they are not depressed. In this study, participants endorsed impairment at baseline and showed significant functional improvements following aripiprazole augmentation. In addition, this study examined the relationship between changes in cognitive function and psychosocial function. Future studies may benefit from the use of similar approaches to evaluating cognitive impairment, and more thoroughly examining its relationship to psychosocial function.

In addition to supporting possible functional benefits of aripiprazole augmentation, the results of this study are both exciting and promising with respect to general evaluation of functional outcomes in MDD for several reasons. First, they support the need to measure functional outcomes in treatment studies of MDD so that the impact of treatments on function, and particularly cognitive function, can be evaluated. There have been few studies conducted that assess the impact of augmentation strategies on cognitive function in treatment-refractory MDD. Levkowitz et al. (2012) assessed self-rated symptoms using the Cognitive and Physical Functioning Questionnaire (CPFQ) in SSRI non-responders who were augmented with S-adenosyl methionine (SAMe) and found significant improvements in verbal recall and a trend toward significance in word finding. Other studies have found marginal cognitive benefits with augmentation approaches such as cholinesterase inhibitors in the elderly depressed (Reynolds et al., 2011; McDermott \& Gray, 2012), but to our knowledge this is one of the first studies examining objective cognitive performance in a wider age range. The results of this study also support the use of targeted treatments to address specific symptoms (e.g., executive function impairments) that may improve the quality of life and functioning of persons with depression. Of great interest is the finding that changes in symptom severity occurred earlier in the course of treatment, whereas psychosocial and cognitive changes were more closely related and occurred later in the course of treatment. These findings are of course preliminary, particularly given the short duration of the trial, but they do indicate the need to better understand the relationship and timing of changes in these important outcomes to help improve the treatment of MDD.

\section{Acknowledgements}

This research was funded by Bristol-Myers Squibb (Sunderajan, PI). TLG has received research funding from NARSAD and consulting fees from $\mathrm{H}$. Lundbeck A/S. PS has also received research support from Lilly USA, LLC and Takeda Pharmaceuticals North America, Inc. BDG has no disclosures to report.

MHT reports that he is or has been an advisor/consultant to, or on the Speakers' Bureaus for: Abbott Laboratories, Inc., Abdi Ibrahim, Akzo (Organon Pharmaceuticals Inc.), Alkermes, AstraZeneca, Axon Advisors, Bristol-Myers Squibb Company, Cephalon, Inc., Cerecor, Concert Pharmaceuticals, Inc., Eli Lilly \& Company, Evotec, Fabre Kramer Pharmaceuticals, Inc., Forest Pharmaceuticals, GlaxoSmithKline, Janssen Global Services, LLC, Janssen Pharmaceutica Products, LP, Johnson \& Johnson PRD, Libby, Lundbeck, Meade Johnson, MedAvante, Medtronic, Merck, Mitsubishi Tanabe Pharma Development America, Inc., Naurex, Neuronetics, Otsuka Pharmaceuticals, Pamlab, Parke-Davis Pharmaceuticals, Inc., Pfizer Inc., PgxHealth, Phoenix Marketing Solutions, Rexahn Pharmaceuticals, Ridge Diagnostics, Roche Products Ltd., Sepracor, SHIRE Development, Sierra, SK Life and Science, Sunovion, Takeda, Tal Medical/Puretech Venture, Targacept, Transcept, VantagePoint, Vivus, and Wyeth-Ayerst Laboratories. In addition, he has received research support from: Agency for Healthcare Research and Quality (AHRQ), Corcept Therapeutics, Inc., Cyberonics, Inc., National Alliance for Research in Schizophrenia and Depression, National Institute of Mental Health, National Institute on Drug Abuse, Novartis, Pharmacia \& Upjohn, Predix Pharmaceuticals (Epix), and Solvay Pharmaceuticals, Inc.

We are especially grateful to our participants. We also would like to thank Carol A. Tamminga, M.D., Communities Foundation of Texas, Inc. Chair in Brain Science, and Chair, Department of Psychiatry, University of Texas Southwestern Medical Center for administrative support, and Kolette Ring for assistance with manuscript preparation.

\section{REFERENCES}

Berman, R. M., Fava, M., Thase, M. E., Trivedi, M. H., Swanink, R., McQuade, R. D. et al. (2009). Aripiprazole augmentation in major depressive disorder: A double-blind, placebo-controlled study in patients with inadequate response to antidepressants. CNS Spectrums, 14, 197-206

Berman, R. M., Thase, M. E., Trivedi, M. H., Hazel, J. A., Marler, S. V., McQuade, R. D. et al. (2011). Long-term safety and tolerability of open-label aripiprazole augmentation of antidepressant therapy in major depressive disorder. Neuropsychiatric Disease and Treatment, 7, 303-312. http://dx.doi.org/10.2147/NDT.S18333

Blair, J. R., \& Spreen, O. (1989). Predicting premorbid IQ: A revision of the national adult reading test. The Clinical Neuropsychologist, 3, 129-136. http://dx.doi.org/10.1080/13854048908403285

Burdick, K. E., Braga, R. J., Nnadi, C. U., Shaya, Y., Stearns, W. H., \& Malhotra, A. K. (2012). Placebo-controlled adjunctive trial of pramipexole in patients with bipolar disorder: Targeting cognitive dysfunction. Journal of Clinical Psychiatry, 73, 103-112. http://dx.doi.org/10.4088/JCP.11m07299

Burris, K. D., Molski, T. F., Xu, C., Ryan, E., Tottori, K., Kikuchi, T. et al. (2002). Aripiprazole, a novel antipsychotic, is a high-affinity partial agonist at human dopamine D2 receptors. The Journal of Pharmacology and Experimental Therapeutics, 302, 381-389. http://dx.doi.org/10.1124/jpet.102.033175

Bymaster, F. P., Calligaro, D. O., Falcone, J. F., Marsh, R. D., Moore, N. A., Tye, N. C. et al. (1996). Radioreceptor binding profile of the atypical antipsychotic olanzapine. Neuropsychopharmacology, 14 87-96. http://dx.doi.org/10.1016/0893-133X(94)00129-N

Cambridge Cognition Limited (2004). CANTABeclipse test administration guide.

Cuijpers, P., Beekman, A. T., \& Reynolds 3rd, C.F. (2012). Preventing depression: A global priority. The Journal of the American Medical Association, 307, 1033-1034. http://dx.doi.org/10.1001/jama.2012.271

Davidson, J. R. (2010). Major depressive disorder treatment guidelines in America and Europe. The Journal of Clinical Psychiatry, 71, e04. 
http://dx.doi.org/10.4088/JCP.9058se1c.04gry

Endicott, J., \& Nee, J. (1993). Quality of life experience \& satisfaction questionnaire: A new scale. Psychopharmacology Bulletin, 29, 321326

Greer, T. L., Kurian, B. T., \& Trivedi, M. H. (2010). Defining and measuring functional recovery from depression. CNS Drugs, 24, 267-284. http://dx.doi.org/10.2165/11530230-000000000-00000

Hamilton, M. (1960). A rating scale for depression. Journal of Neurology, Neurosurgery, and Psychiatry, 23, 56-62. http://dx.doi.org/10.1136/jnnp.23.1.56

Insel, T., Cuthbert, B., Garvey, M., Heinssen, R., Pine, D. S., Quinn, K. et al. (2010). Research domain criteria (RDoC): Toward a new classification framework for research on mental disorders. The American Journal of Psychiatry, 167, 748-751.

http://dx.doi.org/10.1176/appi.ajp.2010.09091379

Jaeger, J., Berns, S., Uzelac, S., \& Davis-Conway, S. (2006). Neurocognitive deficits and disability in major depressive disorder. Psychiatry Research, 145, 39-48. http://dx.doi.org/10.1016/j.psychres.2005.11.011

Kalsekar, I., Wagner, J. S., DiBonaventura, M., Bates, J., Forbes, R., \& Hebden, T. (2012). Comparison of health-related quality of life among patients using atypical antipsychotics for treatment of depression: Results from the National Health and Wellness Survey. Health and Quality of Life Outcomes, 10, 81. http://dx.doi.org/10.1186/1477-7525-10-81

Keller, M. B. (2003). Past, present, and future directions for defining optimal treatment outcome in depression: Remission and beyond. The Journal of the American Medical Association, 289, 3152-3160. http://dx.doi.org/10.1001/jama.289.23.3152

Kurian, B. T., Greer, T. L., \& Trivedi, M. H. (2009). Strategies to enhance the therapeutic efficacy of antidepressants: Targeting residual symptoms. Expert Review of Neurotherapeutics, 9, 975-984. http://dx.doi.org/10.1586/ern.09.53

Landro, N. I., Stiles, T. C., \& Sletvold, H. (2001). Neuropsychological function in nonpsychotic unipolar major depression. Neuropsychiatry, Neuropsychology, \& Behavioral Neurology, 14, 233-240.

Levkovitz, Y., Alpert, J. E., Brintz, C. E., Mischoulon, D., \& Papakostas, G. I. (2012). Effects of S-adenosylmethionine augmentation of serotonin-reuptake inhibitor antidepressants on cognitive symptoms of major depressive disorder. Journal of Affective Disorders, 136, 1174-1178. http://dx.doi.org/10.1016/j.jad.2011.04.059

Mathers, C. D., \& Loncar, D. (2006). Projections of global mortality and burden of disease from 2002 to 2030. PLoS Medicine, 3, e442. http://dx.doi.org/10.1371/journal.pmed.0030442

McClintock, S. M., Husain, M. M., Wisniewski, S. R., Nierenberg, A. A., Stewart, J. W., Trivedi, M. H. et al. (2011). Residual symptoms in depressed outpatients who respond by $50 \%$ but do not remit to antidepressant medication. Journal of Clinical Psychopharmacology, 31, 180-186. http://dx.doi.org/10.1097/JCP.0b013e31820ebd2c

McDermott, C. L., \& Gray, S. L. (2012). Cholinesterase inhibitor adjunctive therapy for cognitive impairment and depressive symptoms in older adults with depression. The Annals of Pharmacotherapy, 46, 599-605. http://dx.doi.org/10.1345/aph.1Q445

McIntyre, R. S., Fallu, A., \& Konarski, J. Z. (2006). Measurable outcomes in psychiatric disorders: Remission as a marker of wellness. Clinical Therapeutics, 28, 1882-1891. http://dx.doi.org/10.1016/j.clinthera.2006.11.007

Mundt, J. C., Marks, I. M., Shear, M. K., \& Griest, J. H. (2002). The work and social adjustment scale: A simple measure of impairment in functioning. The British Journal of Psychiatry, 180, 461-464. http://dx.doi.org/10.1192/bjp.180.5.461
Nelson, J. C., Pikalov, A., \& Berman, R. M. (2008). Augmentation treatment in major depressive disorder: Focus on aripiprazole. Neuropsychiatric Disease and Treatment, 4, 937-948.

Nelson, J. C., Thase, M. E., Bellocchio, E. E., Rollin, L. M., Eudicone, J. M., McQuade, R. D. et al. (2012). Efficacy of adjunctive aripiprazole in patients with major depressive disorder who showed minimal response to initial antidepressant therapy. International Clinical Psychopharmacology, 27, 125-133. http://dx.doi.org/10.1097/YIC.0b013e3283502791

Nierenberg, A. A., Husain, M. M., Trivedi, M. H., Fava, M., Warden, D., Wisniewski, S. R. et al. (2010). Residual symptoms after remission of major depressive disorder with citalopram and risk of relapse: A STAR*D report. Psychological Medicine, 40, 41-50. http://dx.doi.org/10.1017/S0033291709006011

Reimherr, F. W., Martin, M. L., Eudicone, J. M., Marchant, B. K., Tran, Q. V., Pikalov, A. et al. (2010). A pooled MADRS/IDS cross-correlation analysis: Clinician and patient self-report assessment of improvement in core depressive symptoms with adjunctive aripiprazole. Journal of Clinical Psychopharmacology, 30, 300-305. http://dx.doi.org/10.1097/JCP.0b013e3181db320f

Reynolds 3rd, C. F., Butters, M. A., Lopez, O., Pollock, B. G., Dew, M. A., Mulsant, B. H. et al. (2011). Maintenance treatment of depression in old age: A randomized, double-blind, placebo-controlled evaluation of the efficacy and safety of donepezil combined with antidepressant pharmacotherapy. Archives of General Psychiatry, 68, 5160. http://dx.doi.org/10.1001/archgenpsychiatry.2010.184

Rush, A. J., Giles, D. E., Schlesser, M. A., Fulton, C. I., Weissenburger, J., \& Burns, C. (1986). The inventory for depressive symptomatology (IDS): Preliminary findings. Psychiatry Research, 18, 65-87. http://dx.doi.org/10.1016/0165-1781(86)90060-0

Sanislow, C. A., Pine, D. S., Quinn, K. J., Kozak, M. J., Garvey, M. A., Heinssen, R. K. et al. (2010). Developing constructs for psychopathology research: Research domain criteria. Journal of Abnormal Psychology, 119, 631-639. http://dx.doi.org/10.1037/a0020909

Seeger, T. F., Seymour, P. A., Schmidt, A. W., Zorn, S. H., Schulz, D. W., Lebel, L. A. et al. (1995). Ziprasidone (CP-88,059): A new antipsychotic with combined dopamine and serotonin receptor antagonist activity. The Journal of Pharmacology and Experimental Therapeutics, 275, 101-113.

Tadori, Y., Forbes, R. A., McQuade, R. D., \& Kikuchi, T. (2008). Characterization of aripiprazole partial agonist activity at human dopamine D3 receptors. European Journal of Pharmacology, 597, 27-33. http://dx.doi.org/10.1016/j.ejphar.2008.09.008

Thase, M. E., Trivedi, M. H., Nelson, J. C., Fava, M., Swanink, R., Tran, Q. V. et al. (2008). Examining the efficacy of adjunctive aripiprazole in major depressive disorder: A pooled analysis of 2 studies. Primary Care Companion to the Journal of Clinical Psychiatry, 10, 440-447. http://dx.doi.org/10.4088/PCC.v10n0603

Veiel, H. O. (1997). A preliminary profile of neuropsychological deficits associated with major depression. Journal of Clinical and Experimental Neuropsychology, 19, 587-603. http://dx.doi.org/10.1080/01688639708403745

Ware, J. E., \& Snow, K. K. (1993). SF-36 health survey manual and information guide. Boston, MA: Health Institute, New England Medical Center.

Zimmerman, M., Martinez, J., Attiullah, N., Friedman, M., Toba, C., \& Boerescu, D. A. (2012). How should residual symptoms be defined in depressed patients who have remitted? Comprehensive Psychiatry, 54, 91-96. http://dx.doi.org/10.1016/j.comppsych.2012.06.010 